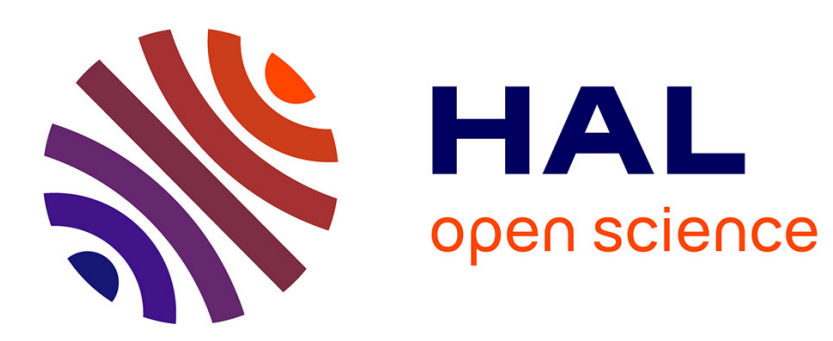

\title{
Local measurements of thermal diffusivity in homogeneous and heterogeneous samples by photoreflectance microscopy
}

\author{
L. Pottier, Karsten Plamann
}

\section{> To cite this version:}

L. Pottier, Karsten Plamann. Local measurements of thermal diffusivity in homogeneous and heterogeneous samples by photoreflectance microscopy. Journal de Physique IV Proceedings, 1994, 04 (C7), pp.C7-295-C7-297. 10.1051/jp4:1994770 . jpa-00253299

HAL Id: jpa-00253299

https://hal.science/jpa-00253299

Submitted on 1 Jan 1994

HAL is a multi-disciplinary open access archive for the deposit and dissemination of scientific research documents, whether they are published or not. The documents may come from teaching and research institutions in France or abroad, or from public or private research centers.
L'archive ouverte pluridisciplinaire HAL, est destinée au dépôt et à la diffusion de documents scientifiques de niveau recherche, publiés ou non, émanant des établissements d'enseignement et de recherche français ou étrangers, des laboratoires publics ou privés. 


\title{
Local measurements of thermal diffusivity in homogeneous and heterogeneous samples by photoreflectance microscopy
}

\author{
L. Pottier and K. Plamann
}

Laboratoire d'Optique de l'ESPCI, Centre National de la Recherche Scientifique et Université Pierre et Marie Curie, 10 rue Vauquelin, 75005 Paris, France

\begin{abstract}
We present a variant of the traditional photoreflectance microscopy. It allows thermal diffusivity measurements on samples as small as a few tens of microns, possibly of mediocre surface quality.
\end{abstract}

In "photoreflectance microscopy", the sample is heated by a modulated laser beam focused by a microscope. A dc probe beam of lower intensity, also focused on the sample by the microscope, is reflected through the latter onto a detector. Because of the modulated heating, the temperature map is modulated, and so are the refractive index and the reflectance as well. The reflected probe intensity therefore contains a small modulation, whose amplitude and phase reproduce those of the temperature modulation at the probed point. They are measured by a lock-in amplifier. Traditionally, both the heating and probe spots are adjusted to coincide (or sometimes held at some small fixed spacing). The sample, mounted on a horizontal 2D translator, is scanned according to a raster pattern so as to obtain an "amplitude image" and a "phase image". These two images essentially show how able heat is to escape each point of the sample (or to diffuse from the heating spot to the probe spot). They display such accidents as cracks, grain joints, etc., at a scale of a few microns up to a few tens of microns. The method requires a surface of honest optical quality.

We introduce a variant method, in which only the heating spot is swept over the sample, while the probe spot and the sample remain fixed. In a homogeneous material, as soon as the spacing of the two spots is larger than the quadratic sum of their diameters [2], the detected phase lag is proportional to the time of propagation of the thermal wave from the heating point to the probed point, i.e. proportional to the spacing of the spots. The phase contour lines are thus circles concentric with the probe spot. The distance $\Delta L$ of two circles and their phase difference $\Delta \Phi$ obey the relation

$$
\Delta L / \Delta \Phi=\mu=[D / \pi f]^{1 / 2}
$$

where $\mu$ is the thermal diffusion length, $f$ is the modulation frequency, and $D$ is the thermal diffusivity. Consequently the thermal diffusivity can be measured, at a typical scale of $10 \mu \mathrm{m}$. Moreover, since optical quality is less critical for absorption than for reflection, only the small area covered by the probe spot has to be of good optical quality. The roughness of the rest of the surface needs only to be less than the microscope's field depth (typically 1 micron) and than 
the Rayleigh divergence lengths of the beams (also of the order of a micron), a much milder requirement. This gives the method good chances of being applicable to materials of poor surface quality.

We also record the $\mathrm{dc}$ component of the reflected heating beam. The resulting reflectance map (some sort of "green micrograph" - heating wavelength = $534 \mathrm{~nm}$ ) is fairly similar to the sample's aspect as seen in the microscope under the white lamp.

Hereafter we present results obtained on gold (to validate the method), then on a magnesia grain in a refractory ceramic, and on a monocrystalline needle in a diamond coating.

Gold was chosen as a well known, unalterable standard. Results obtained at various frequencies from $20 \mathrm{kHz}$ to $1 \mathrm{MHz}$ agree with eq. (1) for the known value $D \approx 1.29 \mathrm{~cm}^{2} / \mathrm{s}$. As conjectured above, a surface scratch strongly affects the reflectance (fig. 1, left) but does not perturb the phase contour lines (fig. 1, right).

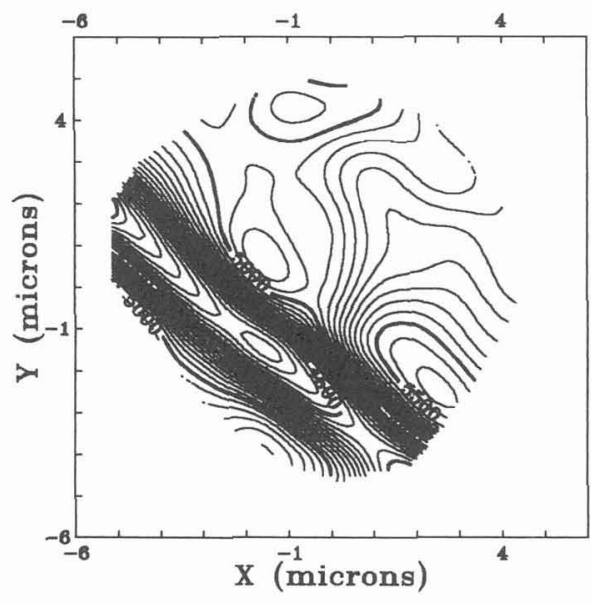

dc green

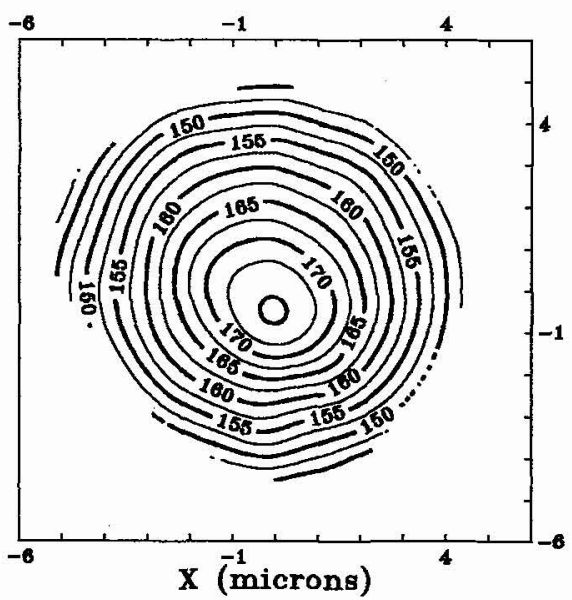

phase

Figure 1: Green reflectance map (left) and phase map (right) obtained on a sample of bulk gold (modulation frequency : $1 \mathrm{MHz}$ ). A surface scratch clearly appears on the reflectance map, but does not perturb the phase of the photothermal signal.

A measurement on a grain of magnesia in a sample of refractory ceramics (coated with a thin film of gold) yielded a diffusivity $D \approx 0.095(0.014) \mathrm{cm}^{2} / \mathrm{s}$, in agreement with values found in a technical report concerning this sample $\left(0.06-0.12 \mathrm{~cm}^{2} / \mathrm{s}\right)$.

Artificial diamond coatings are composed of monocrystalline needles normal to the average plane of the coating. In our diamond sample (also coated with a thin film of gold), the top of one of the needles happens to be a flat cross-section, horizontal under the microscope, of approximate dimensions $19 \mu \mathrm{m} \times 16 \mu \mathrm{m}$. The spacings of the phase.circles at $1 \mathrm{MHz}$ and 100 $\mathrm{kHz}$ yield $D \approx 8-10 \mathrm{~cm}^{2} / \mathrm{s}$ and $D \approx 2.3-2.6 \mathrm{~cm}^{2} / \mathrm{s}$ respectively. A numerical simulation shows that this seeming contradiction can be explained by the reflection of thermal waves on the 
needle's sides, near as compared to the thermal diffusion length. Reflected waves, more retarded than the direct wave, cause the phase lag to increase with the spots' spacing more steeply than in an infinite medium. Together with this simulation, the experimental results lead to the conclusion that the thermal diffusivity of this diamond needle is $\geq 8 \mathrm{~cm}^{2} / \mathrm{s}$.

\section{References}

[1] Rosencwaig A., Opsal J., Smith W.L. and Willenborg D.L., Appl. Phys. Lett. 46 (1985) 1013-1015

[2] Mansanares A., unpublished. 